\title{
Rotaciones y traslaciones en la narrativa de Enrique Jaramillo Levi ${ }^{1}$
}

\section{Fernando Burgos ${ }^{2}$}

University of Memphis, Estados Unidos

\begin{abstract}
$\mathbf{r}_{\text {esumen }}$
Este ensayo examina el concepto de metaficción en los cuentos de Enrique Jaramillo Levi. Se comienza por una explicación de los orígenes de la metaficción en la literatura universal así como de su establecimiento más sólido en el contexto de la narrativa moderna de la literatura escrita en lengua española. Se desarrolla luego la aplicación particular de lo metaficticio en la obra cuentística de Jaramillo Levi dejando claramente establecido que en su caso se trata de un estilo posmoderno cuya plasmación difiere del uso encontrado en la modernidad artística hispana. Finalmente en el análisis de un conjunto específico de cuentos del autor panameño se discute la manera como esas particulares técnicas posmodernas demuestran la función plural de lo metaficcional, contribuyendo así a la riqueza estética de la narrativa de Jaramillo Levi y, por ende, de la centroamericana.
\end{abstract}

\begin{abstract}
This essay scrutinizes the concept of metafiction in Enrique Jaramillo Levi's short stories. The article starts with an explanation regarding the genesis of metafiction in world literature as well as its more solid establishment in the context of modern literature written in Spanish. It continues with the particular uses of metafictional discourse in Jaramillo Levi's short stories by asserting that in his work there is a clear postmodern use whose literary rendition diverges from the one depicted by the works produced during Spanish artistic modernity. Finally, there is a discussion of specific short stories written by Jaramillo Levi, intended to show how those particular postmodern techniques point to the plural functionality of the metafictional
\end{abstract}

1 Ponencia presentada en el XX Congreso Internacional de Literatura Centroamericana (ciLca) 2012. Recibido: 30 de marzo de 2011; aceptado: 12 de junio de 2011.

2 Correo electrónico: fburgos@memphis.edu

$$
L_{\text {etras }} 49 \text { (2011), ISSN 1409-424X }
$$


mode, thus contributing to the aesthetic qualities of Jaramillo Levi's narrative as well as to those of Central American fiction.

Palabras clave: narrativa centroamericana contemporánea, posmodernidad, metaficción, cuento panameño

Keywords: contemporary Central American narrative, postmodernity, metafiction, Panamanian short story

Lo metaficticio es una práctica diseminada de la modernidad aunque si se atendiese a la totalidad de la producción artística universal sus primeras manifestaciones se situarían en el arte de la antigüedad clásica. En lo que respecta a la narrativa occidental se extiende desde la fundación de la novela moderna adelante, correspondiéndole, por tanto, a don Quijote y Sancho cargarlo en los avatares de sus aventuras y en el portal de sus quiméricos proyectos. El cuestionamiento que Cervantes hacía a la unidimensionalidad de la representación de lo real así como la ejecución multívoca de los planos de la ficción constituirían los cimientos del fecundo empleo de lo metaficticio en más de cuatrocientos años de producción artística. En su registro posmoderno la metaficción se piensa como una función de vertientes inagotables y cuyo uso no debe siquiera atenerse a una presencia oblicua cuya sutileza permita su descubrimiento paulatino. Su mostración puede ser frontal y agresiva al punto incluso de que lo metaficcional no se identifique con un uso dentro de lo ficcional sino que advenga como la fuente primaria de realización artística. No obstante, aunque la experiencia de lo metaficcional puede ser más directa en la sensibilidad posmoderna, su funcionalidad se aleja de una comprensión racional para experimentarse como un acto de asimilación — de la manera que lo sería la iluminación del satorimoviéndose en una dirección de retorno hacia el escritor y otra de ingreso del lector en la entraña de la experiencia artística.

La producción metaficcional de Jaramillo Levi abarca el total de su obra, desde Duplicaciones en 1973 hasta Con fondo de lluvia 
en 2011. Su plasmación es variada, como se podrá apreciar en el examen de su cuentística. Una de sus obsesiones en este respecto es la de hacer ingresar en la gestación de la médula literaria al escritor, el lector y la escritura, convirtiendo a los tres en entes de productividad interrelacionados más que en personajes de configuración literaria. Es decir que se trata de una operación de súper concientización sobre una actividad que no abandona en ningún momento su medio ficticio y que por lo tanto no está destinada a ser una representación de lo real ni menos a participar a sus supuestos lectores de una historia ya que la mera idea de que un autor escoja una historia que en su decisión personal contiene un nivel de trascendencia llevaría a situar al escritor en una esfera alta y especial. Esa actitud coincidiría con la jactancia. Una presunción absoluta de la cual el arte posmoderno de Jaramillo Levi reniega. También, el medio ficticio es ultra actuado casi como si, en un paralelo con el teatro, la verdadera función fuese la del ensayo previa a la del estreno de la obra en el cual el director, los personajes, invitados al ensayo y el propio ensayo fueran la materia de una revisión crítica que puede ser detenida en cualquier momento y, particularmente, en la cual no importa que el director se mezcle con los personajes, ni que estos hagan comentarios o rebatan al director, ni que el vestuario o escenario sean los definitivos, ni que toda la pieza actuada se ponga en cuestión, objetando de hecho su estreno y dejándola así en su nivel de incompletitud. Un aspecto de ese acceso metaficcional es el de encontrarse con sus imperfecciones, sus posibles remiendos y sobre todo el de abrirse a reflexiones nacidas en ese momento de integración y, por ende, cambiantes de acuerdo con la particular experiencia de lectura o de reformación de la escritura a la cual abiertamente se ha invitado.

Para ilustrar las consideraciones previas, examinemos el siguiente reproche encontrado en el cuento de Jaramillo Levi «Escritor/texto/lector»: «El texto que leo como cuento parece un engaño, un descarado fraude, pues no hay por parte alguna una verdadera historia, y mucho menos auténticos personajes ni ambientes, por lo 
que no puede haber desenlace alguno a falta de conflicto» (Con fondo de lluvia 106) ${ }^{3}$. Es una recriminación que viene del flanco de la lectura, posibilitada por un escritor preocupado por el desconocimiento de lo estético en una posmodernización social que privilegia la satisfacción instantánea de una literatura fácilmente digerible. Esa invectiva de un lector simplón producto de la cultura posmoderna revela asimismo esa súper conciencia que siente el escritor de escribir sobre el acto de escribir. Es una reconvención ficticia a lo que anticipadamente un lector que carece de pensamiento crítico va a manifestar en el proceso de leer el cuento. En su regaño se revela una falta de comprensión de lo que el arte involucra como posición sociocultural. Frente a ello, el objetivo del escritor será el de desintegrar un concepto de lo que es la literatura formado por el hábito de un discernimiento que en realidad nunca fue artístico. Pero en lugar de eliminar a ese tipo de lector se le conquista sin entretenimientos sino con el potencial de su transformación cultural en un despertar iluminante por el cual ese lector «disfruta de una gozosa epifanía de la que es sujeto y objeto a la vez» (Con fondo de lluvia, 107). Aquí se llega a ese desiderátum de la experiencia metaficcional posmoderna: ser sujeto y objeto creativos a la vez es la aspiración máxima de esta postulación estética para la cual el verdadero devenir del arte ocurriría sólo como una realización de integración.

En «Grietas» se experimenta la realización de un texto creativo susceptible de originarse con cualquier palabra sobre la cual se opere una evocación de la misma. De este modo se convoca el término grietas tres veces como si fuese un conjuro escritural cuyo exorcismo refuta la desolada alternativa de permanecer en la página en blanco. Esas tres llamadas hacen posible tres vías diferentes de textualización aunque no necesariamente de una historia, de suerte que la necesidad de articular esa experiencia a través de protagonistas, ambientes y tramas es refutada o percibida sólo como un relleno.

3 Enrique Jaramillo Levi, Con fondo de lluvia (San José: Editorial Universidad Estatal a Distancia, 2011). 
Lo más vital de la creatividad en esta óptica es la demostración de la existencia textual en sí, en lugar de una creación que deba probar su utilidad: «Éste que, quiérase que no, ha sido creado con recursos mínimos. Texto híbrido que habla de cómo nace de la nada, o de sí mismo, y que reconociendo sus muchos horizontes y limitaciones sabe también que, mal que bien, ya existe» $(\text { Reverso, } 75)^{4}$. El cuento «Mal que bien» por su parte confronta el problema de parálisis creativa y por lo tanto de presumible inconclusión acudiendo, en un intento de evitarlo, a la figura de alteridad del escritor quien muere para que su otro pueda completarlo. La viuda en su papel de lectora rescata los fragmentos de lo que se había logrado escribir y remata el cuento por el hecho de haber leído lo ya existente y confirmar su armazón fragmentaria. Lo que va a prevalecer, sin embargo, son las dudas del escritor adyacentes a las posibilidades ilimitadas de hacer literatura: «No sé si es lícito aludir a los problemas que uno tiene frente al proceso creativo dentro del texto mismo que uno está procurando crear. Sin duda no se trata de un tema demasiado apasionante, nada que el lector común y corriente pueda considerar ameno por su particular interés anecdótico; sin embargo, de que debe tener cierta validez, me parece que sí. ¿Por qué no? Al fin y al cabo se supone que todo tema es válido en literatura, sabiéndolo tratar» (Reverso, 106-107).

La reunión de lo metafísico y lo textual es completamente cabal cuando el fluir de la escritura permite una brillante pieza existencial como en el cuento «Dejando» pero al mismo tiempo su castigo es la disolución del sujeto narrativo y la caída final en el silencio: «Estoy entrando muy suave, lenta, enigmáticamente, en una niebla densa que me atrae como un imán gaseoso. Intuyo que muy pronto habrá de tragarme y no sé si mis recuerdos permanecerán intactos fuera de su influjo o si al absorberme pereceré por siempre perdido en su vorágine como quien penetra en un magma desconocido con todo y la memoria que pueda quedarme de lo vivido» (Reverso, 118).

4 Enrique Jaramillo Levi. Reverso. Versión electrónica facilitada por el autor. 
Ese magma de la nada alerta sobre los pasos finales de la escritura y del escritor indicando que no es tanto un miedo a la muerte lo que intimida sino más bien una evanescencia de todo el orden de lo real, incluyendo el de sus figuraciones simbólicas. El cuento «Todos los días» yuxtapone la mecánica de las repeticiones a que se expone el ser humano cotidianamente a las opciones de salida de ese modo alienante de existencia. La conciencia de una inexistencia de alternativas coloca al sujeto narrativo al margen de la rueda del universo y por tanto de la escritura. El ser humano es el gran excluido. Realización que en una perspectiva nihilista le hace retraerse de la arrogancia de ser para resignarse a la insustancialidad de su constitución y de sus proyectos: «Y poco a poco me voy sosegando. Me conformo. Me acepto como soy. Como estoy. Así nací. Hace mil años, o casi. Pequeñito. Insignificante. Limitadísimo. Inútil. Mancha informe en la pared. Baba de alguien, de mí mismo. Pura conciencia. Conciencia pura. Purísima» (Reverso, 132-133). Lo que queda de este ser arrojado al mundo heideggeriano es la conciencia de ser apenas un punto anodino, ni siquiera de referencia.

«Mini versus Micro» es un cuento construido con las posiciones de un debate entre el autor declarado o testigo en este caso del propio texto que está escribiendo para hacérselo leer finalmente a un crítico español con quien sostiene una discusión. La polémica comprende básicamente dos niveles. En el primero se problematiza la propiedad de los términos 'microrrelato' y 'minicuento'. Mientras el crítico aboga por el uso del vocablo 'microrrelato' e indica que el sufijo 'mini' podría hasta ser peyorativo en España, el escritor ataca la utilización de 'micro' alegando que este sufijo trae a la mente lo prácticamente imperceptible. Satiriza, además, esta expresión, con la observación de que algo 'micro' en el mundo latinoamericano por ser pobremente distinguible habría que verlo con un microscopio En el segundo, el escritor cuestiona el hecho de que la distinción entre minicuento y cuento deba constituirse en una separación de géneros, argumentando que su producción narrativa siempre ha incluido textos 
breves que deberían leerse perfecta y naturalmente como cuentos. El crítico, por su parte, sostiene la necesidad de un distanciamiento genérico entre y una y otra expresión, invocando una estructura interna particular para el microrrelato y muy diferente a la del cuento. Frente a la obstinada defensa del escritor, el crítico amonesta: «Por eso no se te ha dado tu lugar como microrrelatista en el mundo editorial, ni en el de la crítica. Es una lástima porque, lo que sea de cada quien, eres muy buen escritor en ambos géneros', concedió» (Reverso, 24). El escritor mantiene su argumento de que un minicuento para llegar a constituirse como tal debe ser primeramente un cuento, lo cual él intenta demostrar con alusiones a su propia trayectoria, y finalmente con la experiencia de convertir el debate en un texto creativo que se lo da a leer al crítico con el objetivo de refutar su presunción. La inclusión - en el propio territorio del hacer literario- de dos discursos, uno que proviene del campo crítico y otro del creativo pertenece a la tradición de la modernidad. También lo es la polaridad de ambas exposiciones que tiene por objetivo esencial mostrar que la crítica, en su afán de instituirse como disciplina, puede llegar a un nivel extremo de autarquía, alejamiento e incomprensión del arte. Jaramillo Levi explica que el enfoque creativo en el caso de una postura artística metaficticia requiere atender cuidadosamente a su carácter provisional así como a su formulación de tentativa con los límites de la literatura:

Debe entenderse, entonces, que en este tipo de obra hay una actitud indagatoria y, en más de un sentido, experimental, ya que la atraviesa una insistente reflexión en torno a la naturaleza del acto creativo o acerca de los componentes de la obra final que resulta de tal proceso. Pero es menester que esa indagación se realice más bien a trasmano, que se dé como soslayo, y que fundamentalmente se nutra de los procedimientos propios de la ficción literaria, sobre todo tratándose de novelas o cuentos. (Escrito está, 7-8) 
El giro hacia lo posmoderno es realizado en este cuento en la sobredimensión del escritor en cuanto a su estatuto crítico, haciendo patente que un registro teórico es la pertenencia más connatural al medio creativo y que por ende, el arte nunca se desligó de la teoría. La segunda entrada posmoderna consiste en la aplicación de los principios de la metaficción a una experiencia supuestamente viva que va a ser aprovechada como material literario: «Esa tarde, al terminar la primera Mesa Redonda, le entregué el presente texto, cerrado sobre sí mismo en un final en el que me anticipé a la realidad; obviamente metaficcional por los cuatro costados» (Reverso, 25). Tal incorporación de capas que se van envasando una en la otra sugiere un modo diferente de conceptuar lo artístico, uno en que la maquinaria metaficticia no sólo puede absorber la suma de lo real y lo literario sino que también el proceso detrás de ello, dejando completamente expuesto el grado cero de la escritura.

«Maná del cielo» plasma las revelaciones de la conciencia crítica del escritor quién luego de muchos años de producción revisa en su pasado que lo que desciende a su escritura es una especie de flujo continuo, un maná que vigoriza su relación con el mundo. Este nutriente y don que se adhiere a la escritura revela el potencial de una comunicación mística — en el sentido de vinculación a algo otrocon la base de lo creativo como si se tratara de un poder descendiente y asignado que no se puede racionalizar. El escritor — quien se ve a sí mismo como una amalgama de la escritura y de la lectura - emprende un recuento de su obra en el que debe enfrentarse a las posibles arrogancias del artista y con una actitud humilde aceptar que no ha sido un Kafka «quien como se sabe pidió que tras su muerte se destruyera gran parte de su trabajo literario» (Secreto a voces, 158) ${ }^{5}$. En ese vaivén, la conciencia de la construcción temporal del sujeto lo obliga a conceder el punto de arribo a un estado de improductividad: «Hasta que un buen día, ya muy entrado en años, se sintió vaciado de toda posibilidad

5 Enrique Jaramillo Levi, Secreto a voces (San José, Costa Rica: Uruk Editores, 2008). 
de crear algo nuevo sin repetirse, y sencillamente dejó de escribir» (Secreto a voces, 158). Por otra parte, herido frente al conocimiento que depara tal comprensión, debe referirse también a su vanidad. En esta instancia el lector que existe dentro de todo escritor se separa virtualmente de él para realizar un trabajo de recopilación que posibilite la materialización de ese libro total póstumo (incluyendo todo el material inédito). La figura narrativa de un yo-él (escritor-lector) en lugar de caer en la simulación del espejo que haría indistinguible a uno del otro crea un distanciamiento virtual necesario que descompensa momentáneamente la egolatría del escritor para reintegrase a ella posteriormente por medio de la exaltación de su obra. El repaso del tiempo de la escritura que hace ese lector — «Me acuerdo que los cuentos le salían con una facilidad increíble pero lo más sorprendente es que él siempre aseguraba no tener plan alguno en la cabeza, ningún tema en particular, cero estrategia narrativa» (Secreto a voces, 157) crea la ilusión de que quien valora la producción del escritor es un sujeto completamente ajeno a él. Lo cual pretende estar asegurado por una objetividad casi testimonial: «Y yo le creía, porque vi repetirse el fenómeno una y otra vez, a lo largo de un montón de años» (Secreto a voces, 157). Esta supuesta valoración externa que tampoco deja de ser dudosa por su entusiasta tono de admiración es revelada hacia el final del texto como la ejecución de un diálogo ficticio que en el fondo es un monólogo o un desdoblamiento de eficacia narrativa que debe situarse en una zona diferente de lo verdadero. Es la instancia en que el escritor se reconoce como el «primer lector de mí mismo» (Secreto a voces, 158). «Maná del cielo» ensaya una salida de las trampas espejeantes del ego creativo sólo para quedar más cautivo de susredes.

Producir una disquisición creativa sobre los principios técnicos y teóricos del minirrelato, dentro del propio espacio del cuento que se escribe es el cometido de «En una nuez». En principio es un quehacer destructivo ya que luego de haber escrito doce páginas éstas son comprimidas en una pelota de papel a punto de ser arrojada a la basura: «Arrugó entonces entre sus manos el manojo de papeles 
garabateados hasta hacer de ellos una bola compacta» (La agonía de la palabra, 46) ${ }^{6}$. El desmantelar lo creado guarda relación con las ideas de Horacio Quiroga en su «Decálogo del perfecto cuentista». Para el narrador uruguayo entre los diversos principios que deberían practicarse para lograr un cuento de calidad artística se encontraba el de concebir a éste como una novela depurada de ripios, haciendo referencia no sólo al espacio más reducido del cuento sino que también a la idea de magnificar la tensión en el relato. En el cuento de Jaramillo Levi se reconsidera desechar completamente lo escrito y antes de que el manuscrito se pierda en el desecho se le recupera: «Desarrugó de golpe el bulto crepitante y lo extendió frente a sus ojos sobre la mesa de trabajo para volverlo a leer» (La agonía de la palabra, 46). La actividad que sigue al rescate del manuscrito es la verdaderamente creativa, de suerte que de un modo paralelo al hecho de que limpiar una novela de ripio conduce al cuento, purgar al cuento de su exceso lleva al minicuento. En esa compresión de la escritura se arriba a una esencialidad artística en la cual la historia del relato pierde importancia para ser remplazada por el estallido de significantes que pueden revelarse en la cámara de las ampliaciones que permite la lectura así como en el cuento «Las babas del diablo» de Cortázar. El producto final del relato de Jaramillo Levi se presenta en su nueva forma «depurado de ripios» (La agonía de la palabra 46). Es decir que «el texto era ahora un solo párrafo extenso y a la vez apretado al máximo en su significado esencial» (La agonía de la palabra, 46 ).

El tema de implosión narrativa es también plasmado en la poesía de Jaramillo Levi: «A veces es preciso entrar en el alma misma de las cosas; sin andarse por las ramas ir al grano sin más dilación. ¿Pero como saber realmente cuál es el meollo del asunto? ¿Por dónde cavar un certero túnel obviando del todo los eufemismos de la sinrazón?» (Todo el tiempo del mundo, 62) ${ }^{7}$. Dos cuestiones centrales se presentan en este poema dirigido a la calidad sintética de

6 Enrique Jaramillo Levi, La agonía de la palabra (Guatemala: Letra Negra Editores, 2006).

7 Enrique Jaramillo Levi, Todo el tiempo del mundo (Ciudad de Guatemala: Letra Negra Editores, 2010). 
la imagen que validaría el poder de la poesía y de la minificción. El primero es la dificultad de producir artísticamente una imagen que capte la sustancia de la visión. El segundo es que lo absurdo e ilógico no son medios desechables en el alcance de esa visión y que por lo tanto el escritor debería poder contar con un medio más directo y no explicativo si la imagen va a operar efectivamente en diversos significantes. Fundir doce páginas en un párrafo supone trabajar la escritura como un proceso de imágenes que pueda transportar el significante con mayor eficacia narrativa y profundidad artística que la opción de una historia guiada por su soporte anecdótico. El contenido del recién logrado minicuento no importa puesto que lo trascendente es la comprensión de su realización dentro de un cuento corto que aunque es breve no llega todavía al ser medular de la minificción cuya propuesta constituyera uno de los varios aportes significativos de Jaramillo Levi a la ficción cuentística entendida en su rica gama de opciones estéticas.

El minicuento «La verdad sea dicha» coloca el énfasis en el carácter imprevisto de su ejecución, en el sentido de que el aparato de una planificación narrativa deja de ser necesario para acceder a su realización. El minicuento puede llegar a las manos del escritor de un modo casi inadvertido en una cadena de accidentalidades que subraya un sentimiento de antirracionalidad más que el de la mitificación de un medio literario funcionando como un arranque improvisado de creatividad, universalmente válido para cualquier persona. Tampoco es una experiencia arreglada de lo fortuito así como pudo haberse procedido en algunas de las prácticas surrealistas. La posición de irreflexividad se corresponde con una señal fulminantecuyo llamado percusivo llega como un sacudimiento que no causa contrariedades sino inmediata aceptación de aquello que no estaba pero cuya presencia de algún modo formaba parte de los rasos mayores de esa escritura: «Golpeó gozosamente mi espíritu, se transmitió como una electricidad desafiante a las yemas de mis dedos, y de ahí al 
siempre disponible y receptivo teclado, tan leal siempre para lo que se ofrezca» (Justicia poética, 127) .

En otros términos, el minicuento vendría a ser el encuentro de lo insospechado así como lo inadvertido funciona en los cuentos fantásticos de Cortázar: el ingreso a una zona otra pero que siempre había constituido una pertenencia. La espontaneidad de su realización viene a ser el puente de una creatividad diferente, susceptible de producir en niveles artísticos ignorados aunque intuidos en esa escritura que vibra junto con «las vivencias asimiladas... de una confabulación silente» (Todo el tiempo del mundo, 29, 46). El texto «Chispa» lleva la experiencia de la minificción un paso más allá al aceptarse los procedimientos de la escritura automática como ilustración de una construcción absoluta cuya primera condición es la conexión empática entre escritor y escritura, lo cual parece lograrse sólo en el devenir inmaterial del escritor como figura física: «pero esta vez, cuando te animas a propiciar el fenómeno, éste parece adelantársete. No te necesita para nada» (Algo está por ocurrir, 102). De suerte que debe surgir una segunda condición en la cual se descubre que loque en realidad está actuando es el manantial del subconsciente: «El relato, que a fin de cuentas hace lo que quiere, se escribe solo. Incluso ya está por terminar y tú apenas empiezas» (Algo está por ocurrir, 102). Este tipo de experiencia va a conducir finalmente a una total desaparición del escritor en el minirrelato «Anónimo», resultando en una producción que no debe ser firmada por un autor reconocible ya que la revisión enigmáticamente indeterminada y por ende permanente del texto ha generado un nivel de autonomía que lo hace suficiente en una minimización que ha procurado el encuentro de la misteriosa esencialidad de la imagen: «Cuando, reducido a su mínima expresión, leí el relato por última vez, no fui capaz ya de reconocerlo. Simplemente ya no era mío. Y como no sabía de quién era, lo dejé

8 Enrique Jaramillo Levi, Justicia poética (San José, Costa Rica: Editorial Universidad Estatal a Distancia, 2008). 
sin firma, libre de cualquier tutelaje artificial. Desamparado no; pero sí a sus anchas, y anónimo» (Algo está por ocurrir, 126).

El terror de narrar sin decir, de hacerse tautológico, de contar en lugar de imaginar, convierte al texto en un ser viviente al cual debe remecérsele: «poniéndolo de cabeza sacudí el texto un montón de veces para que se le salieran las ocultas polillas de lo innecesario: las repeticiones de conceptos y vocablos, los ripios, las cacofonías» (Algo está por ocurrir, 126). Habiéndosele dado vida al texto y abandonado por tanto su calidad de objeto, éste en su nueva condición de sujeto podrá metamorfosearse multivalentemente en su nueva relación con diversos sujetos lectores. Los elementos mínimos del texto «La evidencia» funcionan como contraste a la altamente cargada situación emocional de infidelidad sugerida en el minicuento de manera que la omisión de la historia venga a disparar el gatillo de su significante. El tono humorístico, además, en la utilización dual del término 'evidencia' en relación a los amantes sorprendidos in fraganti y a la postración en la que ha quedado el agente encargado de informar sobre la infidelidad - por un supuesto uso de un arma de fuego del amante de su esposa - aumenta la curiosidad del lector sobre la historia. Solamente que no es una historia sino una escamoteada escena de celos, rabia, infidelidad y disputa dispuesta a los ojos de lectores voyeuristas que intentan encontrar espejos simultáneos junto al artilugio de una imagen. Así junto con el amante convertido en detective imprevisto: «como era de esperarse, fuiste del todo inoportuno» (Algo está por ocurrir, 101) ${ }^{9}$, también lo pasa a ser el indiscreto lector. Su impertinencia letrada no lo deja paralítico sino deseante. El corolario de esta minificción sugiere que es en la falta de prudencia donde ocurre todo el placer de la lectura.

«Habría que preguntarle al lector» pone en tela de juicio las premisas popularizadas de arquitectura del cuento: «Dicen por ahí que o hay una historia con su desarrollo, clímax y desenlace, o no hay

9 Enrique Jaramillo Levi, Algo está por ocurrir. Versión electrónica facilitada por el autor. 
cuento. Eso lo aprendí en un taller literario de gente muy educadita y cuadrada a morir, y nunca lo he olvidado. Pero tampoco logro nunca ponerlo en práctica, tal vez porque no me convence del todo» (Escrito está, 35). Esa refutación a la percepción más familiar e ingenua con la que se concibe el relato supone la propuesta de una alternativa: si el camino no es una historia ficcionalizada en la cual se puedan distinguir ciertos estamentos distintivos que den sentido a una lectura prejuzgada con el ser así satisfecha en el encuentro de esas peculiaridades depositadas en el orden del hábito, ¿qué ofrecer en su remplazo? Es una disyuntiva que fuerza a asumir el cuento como un debate con sus consiguientes reflexiones en el cual el autor debe desdoblarse en escritor y lector, o el lector en escritor y público. Es un cuento en construcción cuya aceptación concierne una ampliación que exima al género de sus límites, con lo cual su resolución sería posible sólo en la virtualidad de la lectura. Cuando Jaramillo Levi se plantea esta problemática desde el discurso ensayístico señala que «no puede haber metaficción sin que antes exista ficción en una obra; es decir: simulacro creíble o recreación de una realidad, construcción de una verosimilitud a partir de un artificio artístico» (Escrito está, 8).

Afirmación que ya había sido problematizada dentro de la ficción, específicamente en el cuento «A mis espaldas». En este texto el escritor estira al máximo el hilo tensivo que surge de todo texto metaficticio, plasmando el tipo de dudas que surge en medio de su realización: «¿Creación o reflexión; cuento o ensayo? He ahí el dilema» (Todo es nuevo bajo el sol, 65). Esa disyuntiva se resuelve en «A mis espaldas» con la técnica de permitir una narración cuentística más tradicional en el interior de la armazón metaficticia del relato. Para acentuar el artilugio metaficcional se acude a la historia de una mujer que demanda toda la atención del escritor al punto de dejar a éste desprovisto de palabras ya que «mis palabras todas eran para sus oídos: bondadosas, laudatorias, complacientes, obsequiosas siempre: e irremediablemente el verbo se hacía carne múltiples veces al días» (Todo es nuevo bajo el sol, 66). Pero esta realidad es 
una inventada; una ficción a la cual se puede darle las espaldas para que así se prosiga con el cuento de la arquitectura mayor metaficticia que es la que verdaderamente importa. Al procederse de este modo, la ficción que está dentro de la ficción puede ser deshecha y arrojada al inodoro, llamando así la atención del lector sobre el hecho de que la historia de la mujer exigente no es la que importa.

Su significación reside en el hecho de que esa historia se puede trascender, y que en la escritura del diseño metaficcional —que es la ficción que importa - las interrupciones son significantes, creándose a través de ellas el tiempo y el espacio necesarios como para desintegrar el cebo ficticio de la historia. Así, la metaficción ha revelado que lo que se entiende como historia dentro de la ficción no es un hecho o serie de hechos; no es lo que le ocurre a unos personajes determinados sino palabras nutrientes de la ficción, remplazables y desechables. Cuando en «A mis espaldas» se acciona el inodoro cuya agua arrastra la historia enmarcada y simple señuelo que seduce al lector engañándolo, se produce un sentido de satisfacción narrativa: «Todavía oigo correr el agua a mis espaldas tras halar la cadena mientras regreso a la mesa de trabajo y con pulso seguro termino fácilmente este cuento» (Todo es nuevo bajo el sol, 67).

El concepto de evanescencia que representa lo escrito se plasma en «Efímera». El minicuento mostrará, por consiguiente, que las analogías entre escritura y realidad no son completamente cabales. En el orden de lo alegórico, el ciclo de nacimiento y muerte se completa sin dificultades a través de la reencarnación de un anciano que luego de su muerte en un asilo toma el cuerpo de un bebé nacido en una familia de clase alta. El detalle ruptural de ese orden analógico reside en el hecho de que el bebé no llegará a su vida adulta. Lo azaroso aquí es el llanto ininterrumpido del bebé que conduce a su madre a un estado de locura que le hace arrojar al bebé en contra de una pared, matándole. La faceta siguiente de reencarnación del bebé muerto en un «mí» y personaje de la ficción que se escribe desemboca en lo que no puede seguir renaciendo: «Lástima que yo 
no sea esta vez más que una breve ficción del todo efímera, cerrada para siempre sobre sí misma, sin solución de continuidad» (Secreto $a$ voces, 98). De este modo se confirma una vez más que la ficción no representa lo que en el orden de la realidad se denomina vida. La analogía termina en la fugacidad de ambas. Su destino es la muerte y el olvido, pero la existencia es un concepto sociocultural y religioso que cuenta con una valoración de eternidad aun cuando esto último sea cuestionable filosóficamente. La ficción por el contrario desaparece del modo más banal pensable: la omisión de su lectura.

Un joven universitario, a meses de graduarse de Bachiller en Ciencias y Letras, emprende la tarea de escribir minificción como actividad creativa de una de sus clases en el relato «La exitosa tarea de los cinco minicuentos». Armado de cinco palabras, cuya definición ha revisado cuidadosamente en un diccionario, logra llevar a cabo el proyecto encomendado, sintiéndose al final de la experiencia como un escritor que domina bien el oficio. Un pormenor, del cual nunca llegará a enterarse, perturba, sin embargo, el sentido de logro de ese personaje: el verdadero escritor que lo ha hecho escritor se ha burlado de él, manejándolo todo entre bambalinas. Especular desde y sobre la ficción, inmiscuyéndose en los intersticios de la escritura y en las dudas o certezas de los personajes, conlleva en la perspectiva de Jaramillo Levi una óptica estética expansiva, pero que siempre regresa al big bang desde donde se gestó su arte:

Se trata, pues, en algún sentido, de una suerte de endogamia creativa; de partenogénesis literaria, en la cual la ficción se pare a sí misma mientras se mira hacerlo: un fenómeno artístico en el que es posible visualizar un complejo juego de espejos; o bien la imagen de un serpiente hecha de ficción queriéndose comprender mejor a sí misma y que termina mordiéndose la cola. (Escrito está, 8) 
Las minihistorias creadas por ese aprendiz de escritor revelan el afán de concentrarse en una simple y olvidable anécdota. El cuento mayor que incluye los cinco minicuentos satiriza este empecinamiento mostrando los tropiezos y trampas de la creación, en particular el engaño de pensar el oficio de la escritura como el arte de contar una historia. El personaje-escritor se siente satisfecho con la narración de historias artificiosas sin darse cuenta que éstas están desprovistas de una dimensión artística. Por su parte, el escritor-creador del seudoescritor no siente la necesidad de corregirlo. Lo ha dejado en libertad sin detenerse críticamente en el examen de cada uno los minicuentos puesto que el sarcasmo de lo que es exitoso se dirige a las falsas percepciones ignorantes de la complejidad de la literatura. 